\title{
Metodologias Ativas de Aprendizagem auxiliadas por Tecnologias Digitais como potencializadoras do Sistema Atencional
}

\author{
Cheila Graciela Gobbo Bombana ${ }^{1}$, Adriano Canabarro Teixeira ${ }^{2}$ \\ ${ }^{1}$ Instituto Federal de Educação, Ciência e Tecnologias do Rio Grande do Sul (IFRS) - \\ Campus Sertão - Sertão (RS) \\ ${ }^{2}$ Programa de Pós-graduação em Educação - Universidade de Passo Fundo (UPF) - \\ Passo Fundo (RS) \\ cheila.bombana@sertao.ifrs.edu.br, teixeiralupf.br
}

Abstract. With the objective of investigating manifestations of the functions of the Attention System in undergraduate students in relation to educational processes based on Active Methodologies and assisted by Digital Technologies, this article presents a project and definition of theoretical contribution for the accomplishment of the research, which occurs through study bibliography followed by Action Research. The results show that the Active Methodologies, especially Flipped Classroom and Design Thinking, are presented as a pedagogical strategy to facilitate the manifestation of the Attention System, and that such interventions are more likely to succeed when they are aided by Digital Technologies.

Resumo. Com o objetivo de investigar manifestações das funções do Sistema Atencional em estudantes de curso superior diante de processos educativos baseados em Metodologias Ativas e auxiliados por Tecnologias Digitais, este artigo apresenta projeto e definição de aporte teórico para realização da pesquisa, que ocorre por meio de estudo bibliográfico seguido de Pesquisaação. Os resultados mostram que as Metodologias Ativas, em especial, a Sala de Aula Invertida e o Design Thinking, apresentam-se como estratégia pedagógica para facilitar a manifestação do Sistema Atencional, e que tais intervenções têm maiores chances de sucesso quando são auxiliadas por Tecnologias Digitais.

\section{Introdução}

O processo de aprendizagem na educação formal passa por um momento desafiador diante das transformações sociais advindas com as novas Tecnologias Digitais. Este novo contexto social traz muitos desafios para a educação, entre eles, a falta de atenção dos estudantes, um dos principais problemas identificados nas escolas contemporâneas. Neste sentido, Pozo (2008) enfatiza a necessidade de criar novos espaços educacionais e buscar novas formas de ensinar a aprender. $\mathrm{O}$ autor acredita que "as novas tecnologias da informação, em vez de nos escravizar e nos submeter a suas ocas rotinas, [...] multiplicam nossas possibilidades cognitivas e nos permitem o acesso a uma nova cultura da aprendizagem." ( p. 111).

Diante deste quadro, surge o interesse pelas Metodologias Ativas de Aprendizagem que, auxiliadas por Tecnologias Digitais, apresentam-se como 
VIII Congresso Brasileiro de Informática na Educação (CBIE 2019)

Anais do XXV Workshop de Informática na Escola (WIE 2019)

possibilidades metodológicas para tornar o aprendizado mais dinâmico e as aulas mais interessantes para os alunos. Neste sentido apresenta-se estudo investigativo norteado pelo seguinte questionamento: Quais as possíveis influências de processos educativos baseados em Metodologias Ativas e auxiliados por Tecnologias Digitais sobre o Sistema Atencional de estudantes de curso superior do IFRS - Campus Sertão?

A fim de contribuir para elucidar este problema, o principal objetivo do estudo será analisar manifestações das funções do Sistema Atencional em estudantes de curso superior do IFRS - Campus Sertão diante de processos educativos baseados em Metodologias Ativas de Aprendizagem e auxiliados por Tecnologias Digitais. Este propósito se dividirá nos seguintes objetivos específicos: mapear o estado atual do sistema atencional dos estudantes, compreender o funcionamento do sistema atencional em processos de aprendizagem e reunir conhecimentos sobre Metodologias Ativas de Aprendizagem e Tecnologias Digitais que possam favorecer a manifestação das funções do Sistema Atencional.

\section{Métodos}

Este estudo classifica-se como exploratório, que tem como objetivo proporcionar maior familiaridade com o problema, com vistas a torná-lo mais explícito ou a construir hipóteses. (GIL, 2007). Em relação ao procedimento, é uma pesquisa bibliográfica realizada a partir de referências teóricas já analisadas e publicadas por meios impressos e eletrônicos. O estudo bibliográfico que antecede a pesquisa empírica tem como principais referências Pozo (2008) e Sternberg (2008) para a compreensão do Sistema Atencional, e Bacich e Moran (2018) para aprofundamento dos conhecimentos sobre Metodologias Ativas de Aprendizagem e Tecnologias Digitais.

A pesquisa empírica classifica-se como Pesquisa Intervenção Pedagógica de cunho exploratório e será realizada por meio da triangulação dos dados, usando os instrumentos: observação participativa, questionário e grupo focal. A população são estudantes do curso Superior Tecnólogo em Análise e Desenvolvimento de Sistemas, a pesquisa será desenvolvida na disciplina Gerência de Projetos mediada pela pesquisadora. Entre os resultados almejados está a identificação de estratégias pedagógicas, baseadas em Metodologias Ativas e Tecnologias Digitais que facilitem a manifestação das funções do Sistema Atencional e que possam ser empregadas para facilitar e potencializar a aprendizagem dos alunos do IFRS - Campus Sertão.

\section{Resultados e discussões}

A primeira parte do estudo buscou contextualizar processos educativos em situações de educação formal, identificando o conhecimento sobre o sistema de aprendizagem como elemento indispensável para potencializar esses processos. Com base, principalmente, nos estudo de Pozo (2008), nos guiamos pelos componentes da aprendizagem: resultados, processos e condições, dando ênfase aos processos por meio dos quais é possível compreender como aprendemos. Ou seja, quais são os elementos intrínsecos e extrínsecos que podem desencadear nossos processos cognitivos.

Quando entendemos a estrutura do sistema cognitivo, identificamos dois sistemas de memória interligados: a Memória Permanente, que funciona como um depósito de informações, e a Memória de Trabalho, que funciona como uma cabine de comando, buscando informações na Memória Permanente para executar as múltiplas tarefas com as 
VIII Congresso Brasileiro de Informática na Educação (CBIE 2019)

Anais do XXV Workshop de Informática na Escola (WIE 2019)

quais nos deparamos. Esta Memória de Trabalho, conforme Baddeley (1990), é composta pelo Sistema Executivo Central, que é o responsável pelo controle dos recursos cognitivos, que conhecemos habitualmente como processos de atenção. Portanto, seu bloqueio reduz notavelmente a efetividade da aprendizagem em muitas tarefas, especialmente naquelas que necessitam de compreensão.

Contudo, a aprendizagem requer mobilizar o sistema cognitivo mediante múltiplos processos. Para melhor explicar este ciclo da aprendizagem, Pozo (2008) destaca a importância dos processos auxiliares de aprendizagem: motivação, atenção, recuperação e transferência, e consciência. Focamos então na compreensão da atenção e seu Sistema Atencional, cujas funções: controle, seleção e vigilância, são igualmente importantes para despertar, controlar e manter a atenção. Posto que nossos recursos cognitivos são limitados, é preciso selecionar de maneira eficiente onde focá-los e evitar que se esgotem, a fim de viabilizar a aprendizagem.

Sendo o nosso objeto de estudo as manifestações das funções do Sistema Atencional em estudantes de curso superior, seguimos nosso estudo bibliográfico buscando opções metodológicas nas quais podemos basear nossa intervenção.

Considerando que metodologias são as grandes diretrizes que orientam os processos de ensino e aprendizagem e que se efetivam por meio de estratégias, abordagens e técnicas concretas, nos surge como alternativa às Metodologias Ativas de Aprendizagem que, de acordo com Bacich e Moran (2018, p. 4), "são estratégias de ensino centradas na participação efetiva dos estudantes na construção do processo de aprendizagem, de forma flexível, interligada e híbrida [...] expressam-se por meio de modelos de ensino híbridos, com muitas possíveis combinações." Essas metodologias, consideram uma perspectiva de aprendizagem ativa e são norteadas, conforme Diesel, Baldez e Martins (2016), pelos seguintes princípios: o aluno como centro o processo de aprendizagem; o professor como mediador, facilitador, ativador; autonomia; reflexão; problematização da realidade, trabalho em equipe e inovação.

O desenvolvimento destas Metodologias Ativas de Aprendizagem podem ser auxiliados por Tecnologias Digitais, para facilitar a aproximação da realidade em que os alunos estão imersos, favorecendo a interação e o envolvimento dos estudantes com o processo de aprendizagem. Acerca desta possibilidade, Bacich e Moran enfatizam que:

\footnotetext{
A combinação de metodologias ativas com tecnologias digitais móveis é hoje estratégia para a inovação pedagógica. As tecnologias ampliam as possibilidades de pesquisa, autoria, comunicação e compartilhamento em rede, publicação, multiplicação de espaços de e tempos; monitoram cada etapa do processo, tornam os resultados visíveis, os avanços e as dificuldades. (2018, p. 12).
}

Tais abordagens, enriquecidas por tecnologia, caracterizam o Ensino Híbrido. $\mathrm{Na}$ concepção de Bacich (2015), o ensino híbrido é uma das tendências da Educação do século XXI, pois promove uma integração entre o ensino presencial e propostas de ensino online visando a personalização do ensino. Entre os modelos de Ensino Híbrido, a Sala de Aula invertida é o que recebeu maior destaque. O modelo chama a atenção porque inverte completamente a função da sala de aula e pode ser implementado em qualquer contexto na educação formal.

No modelo chamado de Sala de Aula Invertida, os estudantes aprendem em casa por meio de cursos e aulas online, e os professores usam o tempo de aula para práticas ou 
VIII Congresso Brasileiro de Informática na Educação (CBIE 2019)

Anais do XXV Workshop de Informática na Escola (WIE 2019)

projetos orientados. Conforme Christensen, Horn e Staker (2015), no modelo da Sala de Aula Invertida "o período de sala de aula torna-se um tempo de aprendizagem ativa, que milhares de estudos de pesquisa sobre aprendizagem indicam ser muito mais eficaz do que a aprendizagem passiva." (p.43).

Indo ao encontro de nosso objetivo principal, exploraremos a abordagem Design Thinking como possibilidade metodológica para ser integrada ao modelo Sala de Aula Invertida em seus momentos presenciais. Por ser uma "sistemática que tem como objetivo gerar e aprimorar ideias, facilitando o processo de solução dos desafios cotidianos com criatividade e de forma colaborativa" (BACICH; MORAN, 2018, p.15), apresenta-se como possibilidade metodológica potencializadora do Sistema Atencional no processo de aprendizagem.

O processo do Design Thinking permite gerar e aprimorar ideias de forma estruturada. Dividido em cinco fases - descoberta, interpretação, ideação, experimentação e evolução - que orientam o desenvolvimento da abordagem, permite identificar um desafio e construir a solução para ele. De acordo com Rocha (2018), "as etapas do design thinking reúnem métodos da engenharia e do design, combinados com ideias originadas das artes, procedimentos das ciências sociais e insights do mundo dos negócios." (p. 161). Por ser resultado de um conjunto interdisciplinar, é uma abordagem profundamente humana, que depende da habilidade de ser intuitivo, de interpretar o que se observa e de desenvolver ideias que são emocionalmente significativas para aqueles com quem se está trabalhando.

Tabela 1. Relações entre Design Thinking e as funções do Sistema Atencional

\begin{tabular}{|c|l|l|}
\hline $\begin{array}{c}\text { Fase do processo } \\
\text { de Design Thinking }\end{array}$ & \multicolumn{1}{|c|}{ Funções do Sistema Atencional ativadas } & $\begin{array}{c}\text { Princípios sugeridos por } \\
\text { Pozo }\end{array}$ \\
\hline Descoberta & $\begin{array}{l}\text { Seleção na apresentação de uma forma diferente } \\
\text { de aprender, que envolve problemas próximos à } \\
\text { realidade dos estudantes, com os quais eles se } \\
\text { identificam. }\end{array}$ & $\begin{array}{l}\text { Apresentar os materiais } \\
\text { de aprendizagem de } \\
\text { forma interessante, tanto } \\
\text { na forma como no } \\
\text { conteúdo. }\end{array}$ \\
\cline { 2 - 3 } & $\begin{array}{l}\text { Controle para pensar em estratégias de } \\
\text { aproximação do público envolvido de forma a } \\
\text { coletar informações relevantes para entender o } \\
\text { desafio. }\end{array}$ & \\
\hline
\end{tabular}

A partir no conhecimento das ações necessárias em cada fase do Design Thinking, bem como da mecânica do Sistema Atencional e suas funções, é possível relacionar as fases com as funções a serem ativadas. Para exemplificar, ilustramos na Tabela 1 as relações possíveis na fase de Descoberta. Desta forma, foram identificadas as funções majoritariamente ativadas em cada fase do processo, bem como os princípios para ativação, sugeridos por Pozo (2008), que podem ser desenvolvidos em cada fase. Portanto, a partir do estabelecimento destas relações, acreditamos que o uso de estratégias didáticas baseadas em Design Thinking apresentam potencial para ativação do Sistema Atencional dos estudantes.

\section{Conclusões}


VIII Congresso Brasileiro de Informática na Educação (CBIE 2019)

Anais do XXV Workshop de Informática na Escola (WIE 2019)

Este estudo pretende identificar e qualificar manifestações das funções do Sistema Atencional mediante o desenvolvimento de Metodologias Ativas de Aprendizagem, auxiliadas por Tecnologias Digitais, com estudantes de curso superior, buscando identificar as possíveis contribuições desta estratégia pedagógica para a manutenção da atenção dos estudantes.

A situação atual da investigação nos permite as seguintes conclusões parciais: 1) a atenção pode ser considerada a porta de entrada para desencadear o processo de aprendizagem, sendo que, sem ela, a ativação dos outros processos auxiliares fica prejudicada. Não é possível se motivar, transferir ou ter ciência sobre algo que não está ocupando nossa mente de forma clara e vívida, assim, "pode-se afirmar que, em geral, sem atenção, não há aprendizagem, ou, se se quer maior precisão, quanto mais atenção, mais aprendizagem (POZO, 2008, p.147); 2) as Metodologias Ativas se apresentam como estratégias interessantes em que se pode basear a intervenção pedagógica para facilitar a manifestação das funções do Sistema Atencional; 3) as intervenções baseadas nas Metodologias Ativas de Aprendizagem têm maiores chances de sucesso em sua execução quando são auxiliadas pelas Tecnologias Digitais, pois sua abordagem se torna mais interessante, interativa, participativa e dinâmica, facilitando a diversificação de tarefas, o que favorece a manutenção da atenção dos estudantes.

Além disso, percebemos potência da combinação das metodologias Sala de Aula Invertida e Design Thinking como alternativa metodológica para favorecer a ativação do Sistema Atencional em processos de aprendizagem. Os momentos online podem ser dedicados para a apropriação do material de apoio necessário ao desenvolvimento de cada fase da abordagem, já nos momentos presenciais, com o auxílio das Tecnologias Digitais, as tarefas educacionais rotineiras podem ser automatizadas, contribuindo para que professores e alunos possam direcionar sua atenção controlada para as atividades mais desafiadoras e complexas.

\section{Referências}

Bacich, Lilian; Moran, José (Orgs.). Metodologias ativas para uma educação inovadora: uma abordagem teórico-prática. Porto Alegre: Penso Editora, 2018.

Christensen, Clayton M., Horn, Michael B.; Staker, Heather. Blended - Usando A Inovação Disruptiva Para Aprimorar A Educação. São Paulo: Penso Editora, 2015.

Diesel, Aline; Baldez, Alda Leila Santos; Martins, Silvana Neumann. Os princípios das metodologias ativas de ensino: uma abordagem teórica. Revista Thema, Pelotas, v. 14, n.1, p. 268-288, 2017.

Gil, Carlos António. Como elaborar projetos de pesquisa. 4. ed. São Paulo: Atlas, 2007.

Pozo, Juan Ignacio. Aprendizes e mestres: a nova cultura da aprendizagem. Trad. Ernani Rosa. Porto Alegre: Artmed. 2008.

Rocha, Julciane. Design Thinking na formação de professores: novos olhares para os desafios da educação. In:BACICH, Lilian; MORAN, José (Orgs.). Metodologias ativas para uma educação inovadora: uma abordagem teórico-prática. Porto Alegre: Penso Editora, 2018.

Sternberg, Robert J. Psicologia Cognitiva. Trad. Roberto Cataldo Costa. 4 ed. Porto Alegre: Artmed, 2008. 